\title{
Transition to sustainable city: an integrated design approach for transformative districts - a proposal for replicability
}

\author{
A. Boeri, V. Gianfrate, D. Longo \& E. Palumbo \\ Department of Architecture, University of Bologna, Italy
}

\begin{abstract}
Effective strategies for renovation of the existing building stock are essential to meet climate change challenges, improve energy security and alleviate fuel poverty. More than $80 \%$ of existing dwellings will still be in use in 2050 and in need of retrofitting actions. Residential building renovation is one of the objectives of the EU 2050 Roadmap and replicable solutions are needed to meet the EU's ambitious target. The Research Unit of the Department of Architecture of Bologna has developed a feasibility study for renovation of social housing in Bologna, focusing on Bolognina neighbourhood, a 1920s/1960s district with high replication potential. This building stock requires a comprehensive renovation strategy capable of increasing energy performance, improving the quality of living and integrating the district and its community into a more sustainable city vision. The aim is to speed up innovative actions to energy renovation in order to boost transition towards more resilient and efficient environment. An integrated design approach is adopted to develop flexible and non-disrupting solutions, define keydesign parameters and their interrelation at district scale, implementing innovative energy and environmental assessment methodologies. This paper explores the importance of 'replication' in a complex built environment, developing effective strategies at district scale and identifying further researches branches for future transitions to 2050 .
\end{abstract}

Keywords: fuel poverty, social housing, refurbishment, LCA, replication. 


\section{Introduction: specific context and background framework}

The built environment is responsible for more than half of the energy consumption worldwide, significantly contributing - with the $\mathrm{CO}_{2}$ emissions - to the very causes of climate changes. Future projections on global urban population estimate a further growth with $70 \%$ living in cites by 2050 and $80 \%$ living in European cities already by 2020 [1].

The knowledge and technological gap that exists with respect to how emissions from built environment can be mitigated and, simultaneously, how buildings and their occupants can adapt global and local climate must be filled, involving integration of tested knowledge, advanced design strategies, application of innovative technologies and multidisciplinary research.

The refurbishment of EU building stock needs a 2050 horizon to plan the transition towards a low-carbon society as well as to create the necessary attractiveness to enable people to recognize and accept the significant deriving benefits ( $80 \%$ reduction for heating and cooling energy consumption) [2].

The building sector is closely related to three main challenges of EU 2050 Roadmap:

1. creating a mitigation strategy for climate change;

2. fostering energy efficiency and security;

3. fighting against fuel poverty.

The total $\mathrm{CO}_{2}$ emissions of all buildings in the EU countries are greater than those of the building stock in the United States or China, largely as a result of three factors: the age of the existing buildings, the cold climate and the use of gas for heating [3]. The tight interdependency between the mitigative urban environment, its energy reduction potential and the role of human behaviour needs to be explored in the context of the sustainable development of cities and their prosperity. Strategic urban design, master-planning and the management of buildings, spaces and places must be essential parts of any sustainable development and climate change strategy.

In the last few decades European cities (especially those of the middle and northern Countries) have developed robust and effective governance and planning systems to set up pathways to achieve sustainable development and in July 2009, the leaders of the European Union and the G8 announced an objective to reduce greenhouse gas emissions by at least $80 \%$ below 1990 levels by 2050 (Residential sector: $2030 \mathrm{HG}$ reduction challenge: $-37 \%$ to $53 \%$; $2050 \mathrm{HG}$ reduction challenge: -88 to-91\%) (OECD, 2009).

Given the extent of energy consumed by buildings, improving the energy performance of this sector is crucial to ensure long-term global energy security and reduce energy expenditures.

The EU has taken a prominent role in promoting energy security, climate change mitigation and sustainable development, with a range of policy measures; however, policy specifically addressed to reduce the fuel poverty has been limited, despite its clear relationship with climate change. With increasing energy prices (as a result of a number of factors including increasing in wholesale energy costs and environmental levies), economic hardship at the household, and reduced 
national welfare budgets, the trends are likely to worsen rather than improve (see Figure 1) [4]. The main driver of fuel poverty is a "complex interaction between low income and domestic energy efficiency" [5].

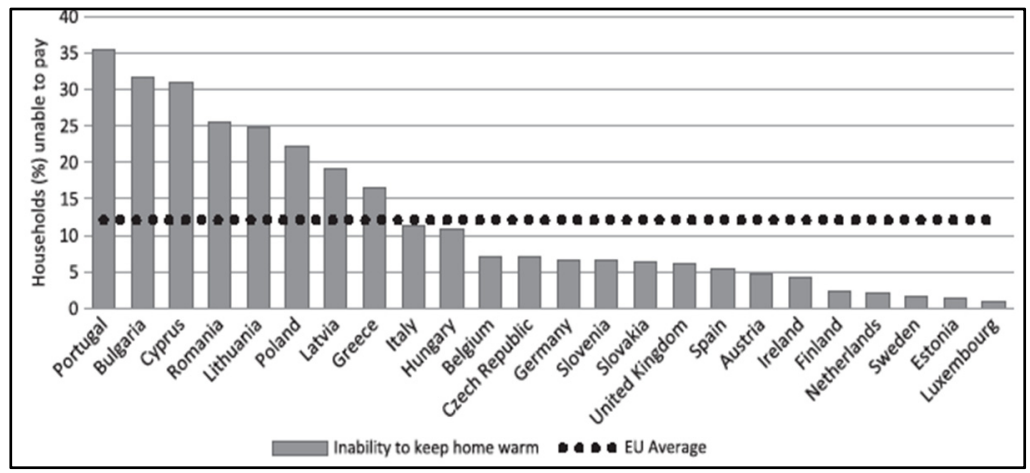

Figure 1: Households (\%) unable to pay to keep their home adequately warm.

Experience shows that improving a building's resistance to the outside elements (e.g. weather proofing) and other energy efficiency improvements (e.g. water heater and piping insulation; replacing old and inefficient appliances, lighting and equipment) are effective in reducing fuel poverty. Many IEA (International Energy Agency) member Countries have recognized the economic development and poverty reduction benefits of low income energy efficiency policy and have implemented weather proofing assistance programmes [6].

\subsection{Residential building stock: low income housing}

The residential building stock is a sector where the penetration of sustainable renovation is slow in spite of the fact that a lot of renovation and modernization activities are undertaken. Barriers to sustainable renovation in the owner occupied market are low-investment capacity and the lack of knowledge about technical solutions. In owner occupied multi-family dwellings an additional barrier is the complex decision making process related to co-ownership of the common building parts (roof, facades, etc.) [7].

Strengthening energy efficiency requirements for existing buildings is more complex to implement. The energy performance of a building envelope, or the components and equipment therein, is only likely to be improved at normal renewal or planned maintenance intervals, often only after the building has been occupied for several decades. The lock-in effect risk is high in the case of existing buildings, especially if investments are made on a component-by-component basis, rather than considering the building as a whole [8].

Several programs in the last decades are addressed to the renovation of the existing building stock, through regulations requiring minimum standards or incentives to encourage energy efficient affordable housing (i.e. Green Deal UK, 
European responsible Housing Initiative, ELENA funding scheme, Funding programmes of KfW and BAFA in Germany, Grid Alternatives, California, etc.).

In the last years the City of Bologna has promoted a renovation program of its building stock. The actions are mostly be addressed to involve social housing areas distributed in different districts of the city, providing 11,889 low-income dwellings. Built during the post IIWW expansion, this building stock requires a comprehensive renovation strategy capable of increasing energy performance, improving quality of living and comfort conditions, and - above all - integrating the district and its community into a smart city vision.

\section{Integrated design approach}

The Research Unit of the Department of Architecture, University of Bologna (UNIBO-RU) is currently involved in the definition of a coherent, articulated and replicable strategy for Bologna social housing stock, to support the Municipality in the achievement of integrated technical solutions to act renovation measures in a reasonable timeframe with a limited disruption for the end-users.

The RU has developed an Integrated Design Approach to identify resilient scenario for renovating existing buildings and districts, as well as to frame effective refurbishment design criteria at district scale.

This integrated design approach combines the excellence in energy efficiency and sustainable projects and technologies with customer oriented strategies in order to ensure the gain creators completely fit with the customers' expectations and requirements.

The aim of the integrated design process (Figure 2) is:

- $\quad$ to establish performance targets for a broad range of parameters;

- $\quad$ to develop preliminary strategies to achieve these targets;

- $\quad$ to iterate the process to produce at least two, and preferably three, concept design alternatives, using energy simulations as a test of progress, and then select the most promising of these for further development.

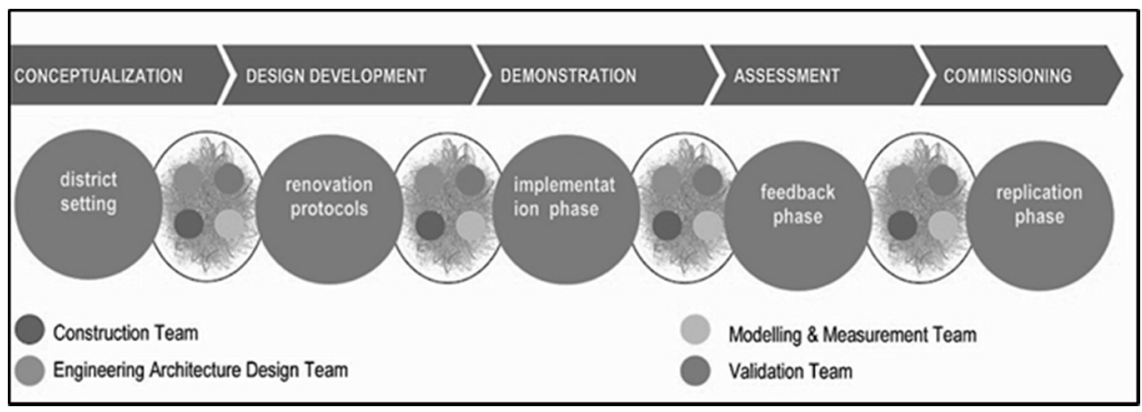

Figure 2: Integrated design process.

The adoption of this process has allowed to obtain qualitative and quantitative results that characterize the nature of the relationship between the demonstration 
sites and energy issues, and to create an integrated design framework for decision support in energy efficiency demonstration project.

\subsection{The case study: Bolognina social housing}

Bolognina neighbourhood is interested since the last two decades by deep transformations. The closure of the big factories during the 1990s has progressively determined a profound social change: the weakening of a connotative identity, the loss of a strategic address and the arrival of new inhabitants has affected the area in a negative manner, attracting inside physical degradation of derelict social decay characterized by the phenomena of petty crime.

The Municipality of Bologna, since the problems emerged, has tried to recognize the origins and define the characters with the aim to overcome them, starting from the recognized potential of the area. The proximity of the history centre and of the station, just as they had led to the genesis, have been able to determine its revitalization. The new population, young and intercultural, creates a dynamism that can become an attraction for many. The administration, since the beginning of the year 2000, has identified the sum of these elements as a potential load to invest significant resources addressed to transform Bolognina in a new polarity (Figure 3-map of Bolognina; Figure 4-demonstration area).

The recent Bologna Strategic Metropolitan Plan aims to provide optimal technical and financial measures for the block houses that will help the renovation of the buildings, thus reducing environmental impact (GHG emissions), increasing the value of apartments, generating income (through lower energy bills), alleviating poverty and creating job positions.

Many factors influence cost-effectiveness of investments in boosting the energy efficiency at buildings and district scale: refurbishment costs, future energy prices, attainable rents, borrowing rates, condition and age of the building as well as a number of other factors.

The RU feasibility study for Bolognina district involves three "trial buildings", selected according to a number of criteria considering their relevance, the building typology involved, the connection to grids or RES at district level, the availability of funds from other parts to support the overall refurbishment action and last, but not least, that they are part of an ambitious vision at a city level.

The buildings are representative of the most widespread typologies in the district, and also in Bologna urban context, to foster the replication of the solutions and to identify a flexible strategy applicable in a large area.

\subsection{The work-plan}

The retrofitting of large areas of a sustainable city needs the set-up of a methodology which - from the concept phase to construction process, from management to maintenance, during all the stages of interventions, from design phase to the end of life at district scale - calls for the cooperation of key stakeholders.

The Bolognina deep retrofit feasibility study includes the following activities: 


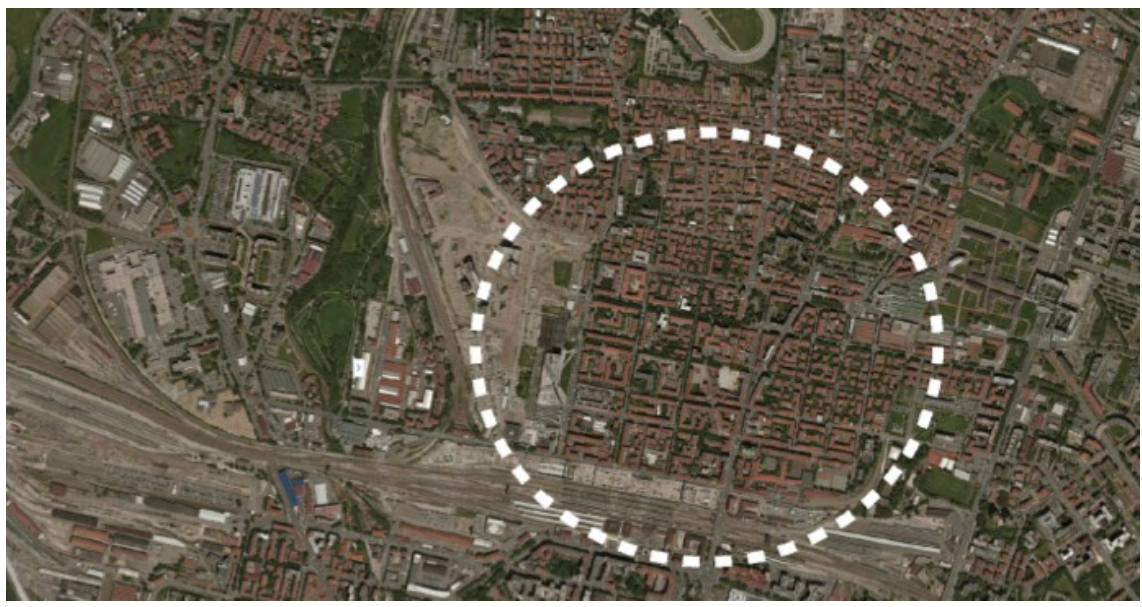

Figure 3: Map of the demonstration area.

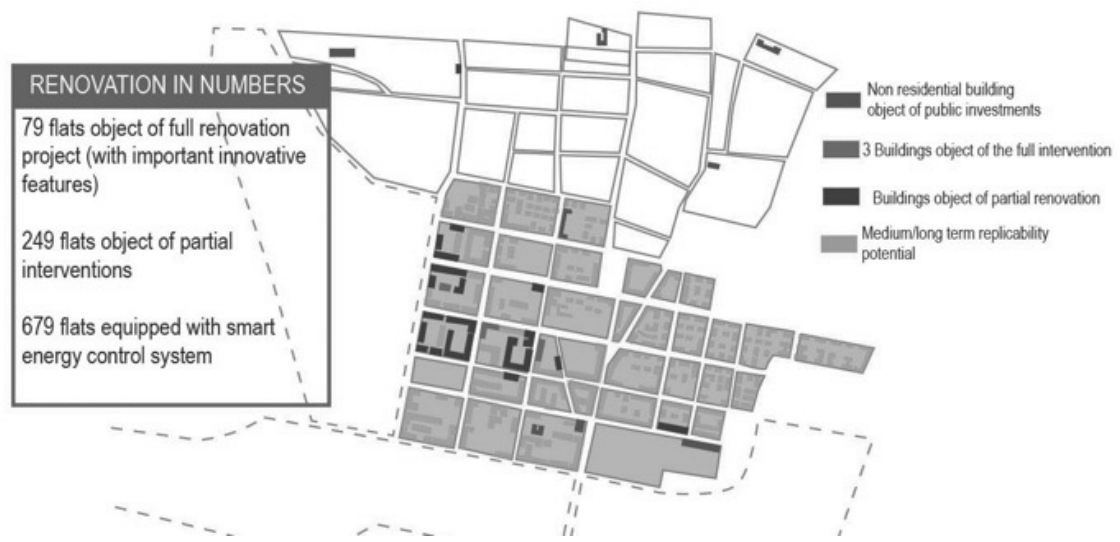

Figure 4: Demonstration area.

1. identification of the key design parameters and the interrelation between them at district scale, accordingly to clear and measurable factors (taking into account the specific climate conditions), to develop strategies and mitigation actions to improve comfort conditions;

2. definition and adoption of design and management protocols to be applied in the operational environment: design strategies (at building and district scale), technological solutions (heating/cooling, ventilation, domestic hot water production - including renewable energy sources (RES) - thermal storage, electrical energy production and distribution, devices for customer awareness about electric consumption, building envelope systems, building components), construction processes, and building management system/district management systems (EMS/BMS/DMS);

3. combination of energy efficiency measures with cost-effective standards at 
district level, with the aim to achieve an improvement of the energy regulatory standards for refurbishment;

4. identification of barriers to the district concept application and proposals of regulation amendments where needed to policy makers;

5. integration between hardware strategies for refurbishment and ICT devices, sensors and dashboards, to accomplish the achievement of a smart management of the building stock, at district and urban scale.

The smart deep retrofit strategy applied to the case studies has envisaged:

- to establish performance targets for each demo-building, based on several indicators, and develop preliminary strategies to achieve these targets to a sub-optimal design solution tailored for the specific demonstrators;

- to define cost-effective retrofitting strategies (comparing retrofitting costs and energy lifetime ones and finding the optimum) through efficient building envelope, application of technologies for refurbishment, and careful consideration of materials in a LCA vision;

- to analyse how to meet heating and cooling loads through the maximum use of renewable technologies, available waste heat sources and the use of efficient HVAC systems (including already existing systems), while maintaining performance targets for indoor air quality, thermal comfort, etc.

The feasibility study, based on the integrated design approach, includes the following tasks:

- identification of constraints (e.g. legal, non-technical ones) that hampers widening the system boundaries (Table 1);

- identification of human behaviour constraints or propensity to improve retrofit technical solution;

- assessment of the impact of the whole neighbourhood (buildings, grid, etc.) on the single building as basis for modelling;

- outlining effective design strategies for improving buildings energy performance;

- defining the key-parameters to achieve energy requirements and high quality standards, introducing key-indicators of quality, energy savings, sustainability, impacts as output of the interoperable platform;

- defining a multi-scale and multi-criteria matrix of parameters to model the effects of each renovation option at building scale on the overall scenario at district scale;

- comparing different scenario with relation to energy balance. In particular:

- energy assessment of possible configurations of district adjacent systems, analysing the system behavior and performance;

- life cycle assessment.

The project, aiming at integrating energy efficiency measures in renovation actions of existing buildings and neighbourhoods, will impact on the comfort and functional conditions of affordable units for low-income classes (social housing typology). The design strategy to be adopted is developed according to the following indicators:

- low cost/cost-effective solutions, both during construction and management phase; 
Table 1: Strategies and barriers to overcome - Bolognina district.

\begin{tabular}{|l|l|l|}
\hline Strategies & Technical barriers & Non-technical barriers \\
\hline Building envelope & $\begin{array}{l}\text { Geometrical constraints } \\
\text { Lack of regulations }\end{array}$ & $\begin{array}{l}\text { Fragmented property } \\
\text { Timing of intervention } \\
\text { Occupied units }\end{array}$ \\
\hline System integration & $\begin{array}{l}\text { Complex design } \\
\text { Suitability with existing } \\
\text { structures } \\
\text { Innovation in the sector }\end{array}$ & $\begin{array}{l}\text { Cultural delay in construction } \\
\text { sector } \\
\text { Supplier companies lobby }\end{array}$ \\
\hline RES supply & $\begin{array}{l}\text { Regulations } \\
\text { Local availability of } \\
\text { resources }\end{array}$ & $\begin{array}{l}\text { Cost effectiveness } \\
\text { Institutional, political and barriers }\end{array}$ \\
\hline $\begin{array}{l}\text { Home automation/ } \\
\text { responsive building }\end{array}$ & $\begin{array}{l}\text { Physical characteristics and } \\
\text { compatibility with } \\
\text { equipment } \\
\text { Resource management }\end{array}$ & $\begin{array}{l}\text { Inhabitants behaviour } \\
\text { Social, political, and personal } \\
\text { context } \\
\text { Starting extra-costs }\end{array}$ \\
\hline
\end{tabular}

- $\quad$ fast work-on-site, reducing the construction time and costs;

- limited disruption for the end-users;

- improvement of the building performance (energy performance during the summer, indoor comfort, thermal bridge reduction and air tightness, integration of equipment control/monitoring system, home automation system integration);

- fuel poverty reduction;

- $\quad$ environmental performance according to LCA (Life Cycle Assessment).

\subsection{Strategies to improve the envelope in Mediterranean climate}

The optimization of the thermal features of the building envelope plays a key-role in achieving high performance, both in winter and in summer conditions. In winter time high level of performances is achieved by adopting different insulation layers according to the orientation of the building envelope. Remarkable results are achieved applying wood windows frame with integration of aerogel panels that allows to reduce the frame section (saving material and resources) while maximizing cost-effectiveness.

Overheating during Mediterranean summer time is reduced adopting a ventilated cladding to be installed over the existing envelope, in particular on the south and west facades.

The ventilation cavity provides a venture effect to extract warm air from the façade while the mass of the wall ensures an adequate thermal lag and temperature dumping. High performance glazed elements avoid dispersion. The RU have developed advanced methodologies for integration and controlled junction systems between windows and wall to ensure adequate air tightness. 


\subsection{The effects of material choice on the life cycle energy assessment}

In order to reduce the life cycle energy consumption and environmental impacts of buildings, most attention has therefore been paid to the operation phase. During their life cycle, the energy required for the buildings is not only related to heating and cooling, lighting and operating appliances, but also the one used to create the building elements (bricks, steel, glazing, etc.) and to use them in construction. Buildings and related products are realized with a variety of materials and each material consumes energy during different stages: manufacture, use and deconstruction/demolition phases [9-10].

This implies that global efforts to reduce emissions in buildings cannot be totally achieved by ignoring the embodied energy.

Scientific community have conducted statistical studies in this field to review the relationship between operational and embodied impacts [11-16]. These studies commonly concluded that the operation stage still accounts for the major part of the life cycle energy use and environmental impact of buildings, but the proportion of the embodied energy and impact is increasing especially in case of low-energy buildings. It was reported that the share of embodied energy in the life cycle energy use (50 years service life) accounts for up to $46 \%$ for low-energy building and up to $38 \%$ for conventional buildings [15]. Furthermore, it has been shown that embodied carbon emission could account for up to $68 \%$ of 60 years life cycle emissions [12].

In this feasibility study the influence of building material choice on the embodied environmental impacts is taken into consideration, together with environmental benefits and material costs for social housing refurbishment in Bologna. The aim is to calibrate the performance of buildings in terms of both embodied and operational emissions in order to reduce total life cycle emissions.

The effects of the choice were studied for the three building component categories: envelope frame, transparent components, and multi-layers components (i.e. insulation) in a comparative way, based on the analysis of the reduction of $\mathrm{CO}_{2}$ emissions; recycling potential; and reduction of emissions embodied in the materials used in the retrofitting and maintenance.

\section{The replication potential}

The study of the UNIBO-RU aims to demonstrate the feasibility of nearly-zero energy building (NZEB) renovation models at district level, in view of triggering large-scale replication of sustainable renovation models across the Emilia Romagna region.

In order to ensure the wide-scale replication and the scalability of interventions, the adopted solutions are thought to maximize the cost-effectiveness and reduce the construction timeframe, reducing the payback period.

The development of the replication and methodology models are pillars of the feasibility study and the initial work was shared with important stakeholders, such as ACER, the Regional Agency which manages the public residential building stock; the Municipality of Bologna, owner of the buildings and Urban Center, 
which is engaged in social initiatives in the neighbourhood to actively involve the citizen in the renovation process; suppliers, to understand the potentiality of application of this approach.

The adopted methodology is addressed to define scaling-up and replication rules which allows to address different district sizes, climatic zones and different energy regulatory regimes, and it is articulated in:

- the definition of retrofitting strategies for different residential building typology (isolated, multi-storey, courtyards buildings, etc.);

- $\quad$ the definition of innovative strategies replicable and scalable in similar urban context, in the city and in the region;

- the development and testing of energy "interface" between buildings and urban fabric, to foster optimal energy efficiency in a larger perspective;

- the combination of ELCA (Energy Life Cycle Assessment) with high efficiency standards, to reach balanced solutions in terms of energy use (both during operating and construction process).

The integrated design approach fosters three scenarios (Figure 5):

- a short-term scenario with the integrated refurbishment of Bolognina social housing blocks;

- a medium-term scenario with the application of the refurbishment methodology to the whole social housing building stock of Bologna;

- a long-term scenario with the involvement of the regional stock of social housing with similar features.

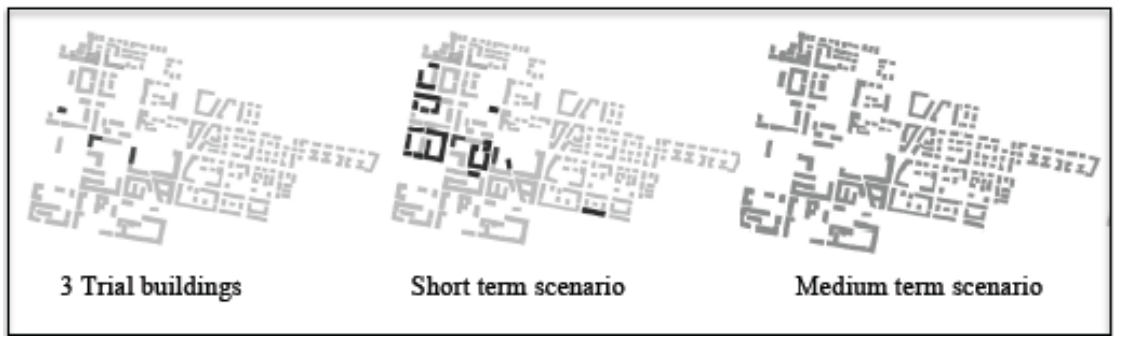

Figure 5: Replication scenarios.

\section{Lessons learned and future research branches}

The UNIBO-RU feasibility study has developed and demonstrated an open and easily replicable strategy for designing, constructing, and managing urban renovation projects to achieve sustainable cities, based on the following pillars:

- $\quad$ studies of cost-effective solutions for the holistic improvement of the energy performance of buildings at district level (definition of standard indicators and new diagnosis approach, analysis of existing energy technologies in a systemic approach);

- deployment of a rigorous measurement and verification of energy performance and savings plan for each demonstrator, taking into account standard protocols, energy regulations, LCA approach. 
The UNIBO-RU has defined a quick and effective detection of the propensity of "individual elements composing the district" (from buildings to grids) to be improved, and it allows to schedule the envisaged actions being aware of the potential deriving impacts in terms of energy efficiency, costs and achievable comfort level. The three buildings, objects of experimentation, have achieved an energy consumption reduction close from $60 \%$ to $80 \%$, with cost-effective and fast-track solutions.

This result could have a huge potential impact for different target groups, such as:

- PAs, to boost the renovation rate of their stock (according to EU Directive 2012/27);

- real estates, to assess the effectiveness of their action plan in terms of payback on large scale projects;

- energy supplier and ESCO, to promote integrated measures including building envelope implementation and RES with customized energy contracts;

- $\quad$ district and citizen communities, to facilitate the creation and adoption on voluntary basis of groups of purchase for energy supply, retrofitting actions, etc.

The next steps for future research branches will be addressed to study effective solutions that allow buildings located in a district to interact with each other and with their immediate urban infrastructures. The combination of future-oriented energy concepts with feasible technical and architectural solutions could answer to the new quality requirements for sustainable districts and cities.

\section{References}

[1] COM (2011) 109: Energy Efficiency Plan (June 2011).

[2] COM (2011) 112: A Roadmap for moving to a competitive low carbon economy in 2050 (08 March 2011).

[3] UNEP, Buildings and Climate Change. Summary for Decision Makings, Paris, 2009.

[4] Heffner G., Campbell N., Evaluating the co-benefits of low-income energyefficiency programmes, June 2011, IEA.

[5] Thomson H., Snell C., Quantifying the prevalence of fuel poverty across the European Union, Energy Policy Journal 52, Elsevier, pp. 563-572, 2013.

[6] Saheb Y., Johnson C., Saussay A., Rozite V., Renovation of the EU buildings stock: an opportunity to reduce the EU gas dependency, ECEEE Summer Study proceedings, Rethink, Renew, Restart, Toulon/Hyères, pp. 123-130, 2013.

[7] Itard L., Fritz M., Towards a sustainable Northern European Housing Stock: figures, facts, and future, Sustainable Urban Area 22, OTB TU Delft, IOS Press PV, Amsterdam, 2008.

[8] Boeri A., Antonini E., Gaspari J., Longo D., Energy Design Strategies for Retrofitting. Methodology, Technologies and Applications, WIT Press, Southampton, pp. 18-21, 2015. 
[9] Takano A., Hughes M., Winter S., A multidisciplinary approach to sustainable building material selection: A case study in a Finnish context. Building and Environment Journal 73, Elsevier, 2014.

[10] Dixit M.K., Fernandez-Solis J.L., Lavy S., Culp C.H., Need for an Embodied Energy Measurement Protocol for Buildings: A Review Paper, Renewable and Sustainable Energy Reviews 16, (2012), pp. 3730-3743.

[11] Mohammed TI, Greenough R, Taylor S, Meida LO, Acquaye A. Operational vs. embodied emission in buildings e a review of current trends. Energy \& Building 66, Elsevier, pp. 232-245, 2013.

[12] Karimpour M, Belusko M, Xing K, Bruno F. Minimising the life cycle energy of buildings: review and analysis. Building and Environment Journal 73, Elsevier 2014.

[13] Verbeeck G, Hens H. Life cycle inventory of buildings: a contribution analysis. Building and Environment Journal 45, Elsevier, pp. 964-967, 2010.

[14] Ramesh T, Prakash R, Shukla KK. Life cycle energy analysis of buildings: an overview. Energy \& Building, 42, Elsevier, pp. 1592-1600, 2010.

[15] Sartori I, Hestnes AG. Energy use in the life cycle of conventional and lowenergy buildings: a review article. Energy \& Building 39, Elsevier, pp. 249$257,2007$.

[16] Thormark C. A low energy building in a life cycle e its embodied energy, energy need for operation and recycling potential. Building and Environment Journal 37, Elsevier, pp. 429-435, 2002. 